\title{
Penerapan Sekolah Berintegrasi Budaya Minangkabau di SMA Negeri 5 padang
}

\author{
Deni Alwidora ${ }^{1}$, Wirdanengsih Wirdanengsih ${ }^{2}$ \\ ${ }^{1,2}$ Universitas Negeri Padang \\ Email: denialwidora28@gmail.com,wirdanengsih69@yahoo.com
}

\begin{abstract}
Abstrak
Penelitian ini bertujuan untuk mengetahui informasi tentang penerapan sekolah berintegrasi budaya Minangkabau di SMA Negeri 5 Padang. Metode dalam penelitian ini menggunakan metode kualitatif, alasan peneliti menggunakan metode kualitatif ini karena peneliti ingin memberi gambaran serta mendeskripsikan tentang penerapan sekolah berintegrasi budaya Minangkabau di SMA Negeri 5 Padang. Penelitian ini menggunakan teknik pengumpulan data berupa observasi, wawancara, dan dokumentasi. Penelitian ini menggunakan teori Struktural Fungsional dari Talcott Parson. Hasil dari penelitian ini yaitu penerapan sekolah berintegrasi budaya Minangkabau di SMA Negeri 5 padang di integrasikan kedalam proses pembelajaran di kelas dan di luar kelas meliputi kegiatan ekstrakulikuler seperti silat dan tarian tradisional, lomba pantun Minangkabau, dan sudut Minang, serta program memakai baju basiba dan menggunakan bahasa Minang setiap hari kamis. Dalam pelaksanaannya terdapat kendala diantaranya masalah biaya yang belum maksimal, kemampuan guru dalam melakukan pengintegrasian, serta kesulitan siswa dalam memahami makna budaya yang di integrasikan tersebut.
\end{abstract}

Kata kunci: Budaya, Minangkabau, Pendidikan

\section{Abstract}

This study aims to find out information about the application of Minangkabau culture integrated schools in SMA Negeri 5 Padang. The method in this study uses qualitative methods, the reason researchers use this qualitative method is because researchers want to give an idea and describe the application of Minangkabau culture integrated schools in SMA Negeri 5 Padang. This study uses data collection techniques such as observation, interviews, and documentation. This study uses the Structural Functional Theory of Talcott Parson. The results of this study are the application of the Minangkabau cultural integrated school in SMA Negeri 5 Padang integrated into the learning process in the classroom and outside the classroom including extracurricular activities such as silat and traditional dances, and the Minangkabau pantun contest, the Minang angle and the program wearing basiba and using language Minang every Thursday, in its implementation there are obstacles including the problem of costs that have not been maximized, the ability of teachers to integrate, and the difficulty of students in understanding the meaning of the integrated culture.

Keywords: Culture, Minangkabau, Education

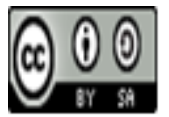

Received: July 29, 2020 Revised: August 17, 2020 Accepted: August 18, 2020

Jurnal Sikola: Jurnal Kajian Pendidikan dan Pembelajaran Vol. 2, No. 1, Th. 2020 


\section{Pendahuluan}

Undang-undang nomor 20 tahun 2003 pasal 3 tentang sistem pendidikan nasional menyatakan bahwa pendidikan nasional berfungsi mengembangkan kemampuan dan membentuk watak serta peradaban bangsa yang bermartabat dalam rangka mencerdaskan kehidupan bangsa dan bertujuan untuk mengembangkan potensi peserta didik agar menjadi manusia yang beriman dan bertakwa kepada tuhan Yang Maha Esa, berakhlak mulia, sehat, berilmu, cakap, krestif, mandiri dan menjadi warga negara yang demokratris serta bertanggung jawab (Muali, 2017)

Pendidikan merupakan sautu usaha yang sangat penting guna menciptakan daya saing dan menemukan jati diri setiap manusia, pendidikan bukan hanya tentang pembelajaran namun juga tentang penanaman nilai untuk membentuk jati diri dan karakter, berarti pendidikan nasional bukan hanya sebatas pembelajaran melainkan juga untuk memebentuk karakter sisiwa (Putri \& Fernandes, 2019).

Pendidikan di Indonesia belum maksimal dalam pelaksanaannya dan belum mencapai tujuan yang ingin di capai, bermunculannya fenomena yang terjadi seperti bully, balapan liar, tauran pelajar, pergaulan bebas, melawan kepada guru, dan mengonsumsi obat terlarang (Zulkifli \& Wirdanengsih, 2020). Fenomena ini sangat jauh dari tujuan pendidikan dan tidak sesuai dengan nilai-nilai budaya Minangkabau, karena itulah diperlukan pengintegrasian nilainilai budaya minangkabau kedalam proses pendidikan.

Tetapi pendidikan saat ini hanya mengutamakan aspek penilaian dalam bidang keilmuan semata sehingga pembentukan nilai;nilai budaya bangsa terpinggirkan, padahal budaya bangsa dapat menguatkan eksistensi suatu bangsa dan Negara (Kunci, 2012). Sehingga budaya bangsa sangat perlu diIntegrasikan dalam pendidikan agar tidak terpinggirkan dan dapat dilestarikan keberadaannya.

Pendidikan bukan hanya tentang kecerdasan melinkan darus diseimbangkan dengan budu pekerti dan nilai yang baik, nilai luhur dalam budaya harus diwariskan melalui pendidikan, agar dapat melahirkan dan membimbing generasi muda, pendidikan Indonesia juga mengalami masalah diman kebudayaan dan pendidikan mengalaim sedikit pemisahan sehingga mengakibatkan transfer nilai-nilai luhur yang terdapat di kebudayaan menjadi terbatas (Sulhan, 2018)

Untuk mencapai tujuan pendidikan serta menanamkan nilai budaya kepada siswa Dinas Pendidikan Provinsi Sumatera Barat mengeluarkan program pengintegrasian budaya alam Minangkabau ke sekolah melalui surat keputusan nomor 420.02/5082/P. SMK. 2019 yang menyatakan bahwa sekolah harus mengintegrasikan Al Quran dan budaya Alam Minangkabau dalam proses pembelajaran di sekolah.

Budaya Minangkabau merupakan salah satu suku bangsa besar di Indonesia yang berasal dari Ranah Minang yang menganut system kekerabatam Matrilineal atau bardasarkan keturunan ibu dan merupakan salah satu kekayaan budaya lokal yang ada di Indonesia, suku Minang mempunyai cirri utama yang khas seperti aturan yang kuat mengenai islam , matrilineal dan kebiasaan merantau (Fransyaigu, 2015).

Pendidikan berintegrasi budaya adalah wujud dari pendidikan yang digerakan oleh budaya dan bertumpu pada prinsip budaya guna menciptakan budaya yang lebih bernilai dari yang pernah ada, pendidikan berintegrasi budaya juga dijadika sebuah cara untuk menyadarkan masyarakat agar belajae seumur hidup guna mengatasi tantangan hidup yang berubah-ubah dan berat, artinya masyarakat yang memiliki budaya sebagai aktor pendidikan dapar membantu terciptanya pendidikan yang melingkupi budaya mansyarakat itu sendiri (Tanu, 2016).

Antara pendidikan dan kebudayaan memiliki hubungan yang kuat, kebudayaan berperan sebagai masukan dalam pendidikan, tujuan pendidikan di sesuaikan dengan perwujudan budaya di masyarakat seperti nilai-nila yang di yang menentukan metode dan kirikulum dalam pendidikan, pendidikan juga bias dijadikan alat untuk menjaga kelestarian budaya serta 
mengontrol masyarakat agar lebih baik, kelestaran dapat dilakukan dengan mewarisi nilai-nilai tersebut kepada generasi muda dengan demikian kebudayaan yang ideal milik masyarakat dapat dilestarikan (Sulfemi, 2019). Buadaya daerah juga diartikan sebagai budaya yang ada di daerah tertentu dan mempunyai unsure-unsur digunakan dalam pembangunan berkelanjutan (Ilmi, 2015).

Pada waktu dahulu budaya atau adat Minangkabau semarak karena masing-masing komponen masyarakat sangat peduli pada pemahaman, pengalaman, dan pembelaan terhadap nilai-nilai agama dan budaya Minangkabau, namun sekarang masyarakat Minangkabau mengalami kegoncangan budaya yang menyeret orang untuk mencari jalan hidupnya sendiri dengan kontrol sosial budaya yang lemah (Abdurahman, 2011).

Dengan dikeluarkannya surat keputsan dinas pendidikan Provinsi Sumatera Barat nomor 420.02/5082/P. SMK. 2019 tentang penyelenggaran pengintegrasian budaya Minangkabau de sekolah menunjuk SMA Negeri 5 Padang sebagai sekolah percontohan dalam penerapannya, SMA Negeri 5 Padang sudah memmulai program tahun 2017 dan sepenuhnya dilaksanakan setahun berikutnya yaitu tahu 2018 .

Berdasarkan observasi peneliti menemukan bahwasanyan pengintegrasian budaya Minangkabau di integrasikan kedalam beberapa proses pendidikan yaitu: 1) budaya Minangkabau di integrasikan kedalam mata pelajaran di sekolah, 2) budaya Minangkabau di Integrasikan ke dalam kegiatan ekstrakulikuler, 3) dan Budaya Minangkabau di integrasikan melalui program-program yang dibuat oleh sekolah

Alasan peneliti memilh SMA Negeri 5 Padan sebagai lokasi penelitian karena SMA Negeri 5 padang merupakan sekolah favorit dan ter akreditasi A yang memiliki prestasi yang meningkat disetiap tahunnya, pada tahun 2016 total 7 piala, 2017 sebanyak 32 piala, dan pada 2018 meraih 53 piala, SMA Negeri 5 Padang juga ditunjuk sebagai salah satu sekolah piloting dalam penerapan sekolah berintegrasi budaya Minangkabau sesuai yang tertulis didalam surat keputusan Dinas Pendidikan Provinsi Sumatera Barat. SMA Negeri 5 Padang serta lingkungan yang masih memegang nilai-nilai budaya Miangkabau

Pelaksanaan program sekolah berintegrasi budaya diharapkan dapat menjadi sarana bagi siswa untuk membentuk karakter serta dapat mengenal dan memahami budaya Minangkabau. Penerapan Sekolah Berintegrasi Budaya Minangkabau sesuai dengan misi SMA Negeri 5 Padang yaitu meningkatkan karakter peserta didik melalui pendidikan Al Qur'an dan Budaya Alam Minangkabau. Namun berdasarkan hasil observasi dan wawancara awal yang peneliti lakukan kepada beberapa siswa, bahwa program tersebut belum membantu siswa dalam mengenal dan memahami budaya Minangkabau. Ini didukung oleh pernyataan ibu Karnalis selaku wakil kurikulum di SMA Negeri 5 padang mangatakan didalam pelaksanaan program ini masih ada siswa yang belum terkontrol dan hanya dilakukan oleh siswa yang berminat saja, dan pelaksanaan nya masih terbatas

Beberapa penelitian yang relevan dan berhubungan erat dengan pembahasan dalam penelitian ini yaitu:

Penelitian yang dilakukan oleh Darul Ilmi (2015) yang berjudul Pendidikan Karakter Berbasis Nilai-nilai Kearifan Lokal Melalui Ungkapan Bijak Minangkabau. Penelitian ini membahas tentang Kearifan lokal dalam adat Minangkabau dengan filosofisnya "Adat basandi syara', syara' basandi kitabullah" merupakan pedoman hidup orang Minangkabau. Pendidikan karakter yang dikembangkan dari ungkapan-ungkapan bijak adat Minangkabau antara lain: Iman dan takwa, disiplin, toleransi, tanggung jawab rendah hati dan tidak sombong, mandiri, kerja keras, komunikatif, amanah, bersahabat, semangat kebangsaan, kreatif, demokratis serta peduli lingkungan. Perbedaan dengan peneliti yaitu peneliti ingin meneliti tentang penerapan sekolah berintgrasi kebudayaan Minangkabau di SMA Negeri 5 Padang, sementara penelitian ini mengkaji tentang pendidikan karakter berbasis kearifan lokal melalui ungkapan bijak Minangkabau.(Ilmi, 2015) 
Penelitian relevan yang lain adalah Rendra Sakbana Kusuma (2018) yang berjudul Peran Sentral Kearifan Lokal dalam Peningkatan Kualitas Pendidikan. Penelitian ini membahas tentang peran serta kearifan lokal dalam meningkatkan proses dan peningkatan kualitas pendidikan. Pendidikan dapat memanfaatkan karakter dan ciri khas setiap daerah dalam mempelajari berbagai fenomena alam dan sosial sehingga pendidikan menjadi lebih bermakna. Melalui kearifan yang dimiliki, bangsa Indonesia dapat mengantisipasi arus budaya asing yang mencoba untuk mempengaruhi karakter dan budaya bangsa Indonesia. Persamaananya dengan peneliti yaitu sama-sama mengkaji tentang budaya dalam pendidikan. Perbedaannya dengan peneliti yaitu peneliti ingin melihat bagaimana penerapan sekolah berintegrasi budaya Minangkabau di SMA Negeri 5 Padang (Kusuma, 2018).

Penelitian selanjutnya Naela Khusna Faela Shufa (2018) yang berjudul Pembelajaran Berbasis Kearifan Lokal di Sekolah Dasar: Sebuah Kerangka Konseptual. Penelitian ini membahas tentang pengintegrasian kearifan lokal dalam pembelajaran sebagai upaya menciptakan pembelajaran yang bukan hanya membekali siswa dalam hal pengetahuan, tapi juga menciptakan rasa cinta terhadap keberagaman lokal di lingkungannya. Perbedaannya dengan peneliti yaitu peneliti ingin meliha bagaimana penerapan sekolah berintegrasi kebudayaan Minangkabau di SMA Negeri 5 Padang. Sedangkan persamaannya yaitu samasama melihat kebudayaan di dalam Pendidikan (Khusna, Shufa, \& Artikel, 2018).

\section{Metode Penelitian}

Penelitian ini dilakukan di SMA Negeri 5 Padang dan menggunakan metode kualitatif. Alas an peneliti menggunakan metode kualitatif karena penelitian ini berusah mendeskripsikan atau memeberi gambaran tentang penerapan sekolah berintegrasi budaya Minangkabu di SMA 5 Paadang, penelitian ini merupakan penelitian kualitatif dengan tipe studi kasus intrinsik yag menekankan pada pemahaman yang mendalam, penelitian ini menggunakan analisis deskriptif (Crasswell, 2016) Alasan peneliti memelih SMA Negeri 5 Padang karena merupakan sekolah favorit dan ter akreditasi A serta juga ditunjuk sebagai sekolah piloting dalam pengintegrasian budaya Minangkabau.

Agar mendapatkan data yang relevan dengan permasalahan penelitian maka infirman dari penelitian ini adalah guru-guru di SMA 5 Padang, Kepala Sekolah SMA Negeri 5 Padang, siswa, penanggung jawab program. Dalam pengumpulan data peneliti menggunakan cara observasi, wawancara dan dokumentasi, disini peneliti melkukan observasi kegiatan yang berintegrasi budaya Minangkabau di sekolah.

Teknik wawancara yang digunakan dalam penelitian ini menggunakan teknik wawancara mendalam dan terstruktur untuk mengetahui sejauh mana penerapan pengintegrasian budaya Minangkabau di SMA Negeri 5 Padang. Wawancara dilakukan dengan mempersiapkan pertanyaaan mengenai permasalahan penelitian, dengan mempersiapkan instrument penelitian dan alat-alat yang sekiranya bis membantu saat dilakukannya penelitian.

Dokumentasi dalam penelitian bisa berupa catatan arsip, tulisan, dan gambar yang monumental, dokumentasi dilakukan untuk mendukung data observasi dan wawancara yang sudah didapatkan (Sugiyono, 2009). Untuk pengecekan keabsahan data yang sudah dikumpulkan menggunakan triangulasi data. Triangulasi data merupan suatu tekni untuk memeriksa keabsahan data dengan memanfaatkan hal-hal yang berada di luar data tersebut, dengan tujuan sebagai pembanding bagi data yang telah peneliti dapatkan, triangilasi dalm penelitian ada tiga macam yaitu triangulasi sumber, metode, dan teori (Ghony. \& Almanshur, 2016)

\section{Hasil dan Pembahasan}

Berdasarkan Undang-undang No 20 tahun 2003 bahwa pendidkan di Indonesia berfungsi untuk watak serta peradaban bangsa yang bermartabat dalam rangka mencerdaskan kehidupan 
bangsa dan bertujuan untuk mengembangkan potensi peserta didik agar menjadi manusia yang beriman dan bertakwa kepada tuhan Yang Maha Esa, berakhlak mulia, sehat, berilmu, cakap, krestif, mandiri dan menjadi warga negara yang demokratris serta bertanggung jawab.

Dimana semua tujuan dari pendidikan tersebut ada di dalam kebudayaan khusunya budaya Minangkabau. SMA Negeri 5 Padang merupakan sekolah yang berintegrasi budaya Minangkabau sesuai yang tertulis di dalam surat keputusan Dinas Pendidikan Provinsi Sumatera Barat Nomor 420.02/5082/P.SMK-2019. Berdasarkan penelitian yang peneliti lakukan bahwasan nya pengintegrasian kebudayaan minangkabau meliputi semua aspek pembelajaran di SMA Negeri 5 Padang, seperti krgiatan pembelajaran dikelas, kegiatan ekstrakulikuler, aturan sekolah yang disesuaikan dengan nilai budaya Minangkabau, serta kegiatan dan programprogram penunjang dalam mencapai tujuan pengintegrasian sebagai berikut:

\section{Pengintegrasian budaya Minangkabau di SMA Negeri 5 Padang}

Pengintegrasian budaya Minangkabau di SMA Negeri 5 padang sudah dimulai sejak tahun 2017, dengan melakukan pengintegrasian budaya minangkabau kedalam semua mata pelajaran, serta kegiatan lainnya yang ada di SMA Negeri 5 Padang.

\section{Pengintegrasian ke dalam mata pelajaran}

Pengintegrasian budaya Minangkabau ke dalam mata pelajaran, nilai-nilai yang diintegrasikan kedalam mata pelajaran seperti nilai-nilai Sumbang 12, nilai-nilai tersebut harus disesuaikan dengan mata pelajaran yang akan diajarkan oleh guru mata pelajaran, pendintegrasikan dimulai dari pembuatan RPP lalu disesuaikan dengan materi ajar. Prosess pengintegrasian ini diserahkan sepenuhnya kepada guru mata pelajaran.

\section{Program sekolah}

Selain ke mata pelajaran SMA Negeri 5 Padang juga mengadakan program-program yang diintegrasikan dengan budaya Minangkabau, program yang berintegrasi budaya Minangkabau diantaranya: pertama sudut Minang, sudut Minang merupakan suatu program yang dibuat oleh sekolah yang di dalamnya terdapat pelaminan tradisional khas Minang, permainan tradisional Minangkabau, serta ada buku-buku tentang adat Minangkabau, sudut Minang ini juga dapat digunakan untuk sisiwa yang ingin mengenal dan mempelajari tentang budaya Minangkabau. Kedua, SMA Negeri 5 Padang juga mengintegrasikan budaya Minangkabau kedalam kegiatan ekstrakulikuler seperti sudah adanya ekstrakulilkuler silat, ekstrakulikuler tarian tradisional pembelajaran tentan pentun-pantun adat Minangkabau serta pembelajaran tentang nilai dan makna yang terkandung di dalam sumbang 12 . Ketiga, selain diintegrasikan ke dalam program sekolah, pengintegrasian juga diterapkan ke dalam peraturan sekolah seperti memakai baju basiba bagi setiap warga sekolah pada hari kamis dan memakai bahasa Minang untuk berinterakasi ini diterapkan pada setiap hari kami juga.

Dalam pengintegrasian program ini tentu sangat membutuhkan dukungan sekolah, SMA Negeri 5 Padang sebagai sekolah piloting sudah berupaya mendukung penerapan kegiatan tersebut, sekolah sudah mengadakan sarana berupa baliho besar tentang sumbang 12 yang dapat dibaca oleh sisiwa agar dapat membantu sisiwa dalam memahaminya. Sekolah juga telah mengadakan sarana lain seperti menyediakan pakaian-pakaian tradisional Minangkabau yang dapat digunakan oleh siswa.

Dalam pengintegrasian ini tentu mngalami beberapa hambatan, hambatan pertama yaitu masalah alokasi dana, sekolah belum bisa mengadakan alokasi dana secara maksimal, akibatnya penerapan program tidak sesuai dengan waktu yang diharapkan karena harus disesuaikan dengan dana yang ada. Kedua yaitu hambatan dari guru, tidak semua guru mampu mengintegrasikan nilai-nilai budaya Minangkabau ke setiap materi yang diajarkan, karena tidak semua materi yang bisa diintegrasikan, dan tidak semua guru juga memeiliki pengetahuan tentang budaya Minangkabau, banyak guru yang hanya mengandalkan pengalaman sehari-hari saja, serta keterbatasan buku referensi yang masih terbatas, ketiga yaitu hambatan dari sisiwa,

Jurnal Sikola: Jurnal Kajian Pendidikan dan Pembelajaran Vol. 2, No. 1, Th. 2020 
hambatan ini berasal dari siswa yang bukan suku Minangkabau, mereka mengalami kesulitan dalam memahami budaya Minangkabau pada saat proses pembelajaran.

Berdasarkan hasil penelitian diatas, pengintegrasian Budaya Minangkabau di SMA Negeri 5 Padang, hal tersebut dapat dianalisis menggunakan teori structural fungsional menggunakan AGIL yang dikemukakan oleh Talcott Parsons. menurut teori struktural fungsionalis ini masyarakat adalah "suatu sistem sosial yang terdiri atas bagian-bagian atau elemen yang saling berkaitan dan saling menyatu dalam kesimbangan. Parsons percaya bahwa ada empat imperative yang diperlukan atau menjadi seluruh sistem adaptasi AGIL atau pemeliharaan pola.

Pertama adaptasi, SMA 5 Negeri Padang sebagai sebuah sistem dalam pendidikan harus beradaptasi dengan budaya dimana sekolah itu berada, SMA Negeri 5 Padang berada di daerah berbudaya Minangkabau, sehingga sekolah harus beradaptasi dengan lingkungan tersebut, agar tetap terjadi keseimbangan antara pendidikan dengan kebudayaan dengan cara memasukan budaya Minangkabau kedalam proses pendidikan di sekolah.

Kedua goal, pengintegrasian Budaya Minangkabau di SMA Negeri 5 Padang yaitu agar siswa dapat mengenal memahami Budaya Minangkabau dan juga Memperkenalkan Budaya Minangkabau yang sudah jarang ditemui saat sekarang ini di tengah-tengah Masyarakat.

Ketiga integrasi, dalam hal ini seluruh warga sekolah SMA 5 Padang harus saling mendukung dan bekerja sama dalam melaksanankan penerapan sekolah brintegrasi budaya Minangkbau ini, peneran akan berjalan dengan baik kalau komunikasi antar komponenkomponen di suatu sistem berjalan dengan baik dalam hal ini yaitu seluruh warga sekolah.

Keempat latency (pemeliharaan pola), Pemeliharaan pola yang dilakukan sekolah agar penerapan sekolah berintegrasi budaya Minangkabau di SMA Negeri 5 Padang dapat terlaksana adalah dengan mengintegrasikan Budaya Minangkabau dalam selur aspek pembelajaran di sekolah mulai dari proses pembelajaran dikelas, kegiatan harian, kegiatan ekstrakulikuler, dan kegiatan yangsifatnya tahunan seperti lomba-lomba.

\section{Kesimpulan}

Berdasarkan hasil penelitian yang telah dilakukan dapat disimpulkan bahwa penerapan sekolah berintegrasi budaya Minangkabau di SAM negeri 5 padang sudah berjalan dengan baik, dimana penerapannya sudah meliputi seluruh aspek pembelajaran disekolah, diantaranya: pertama, sudah diintegrasikan kedalam proses belajar mengajar di kelas melalui rpp yang disesuaikan dengan materi saat itu, kedua, diintegrasikan kedalam karakter sisiwa dengan mananam nilai-nilai budaya Minangkabau seperti Sumbang 12, ketiga, diintegrasikan dalam kegiatan ekstrakulikuler, ekstrakulikuler di SMA Negeri 5 Padang yaitu silat, tarian tradisional Minangkabau dan Pantun-pantun Minangkabau. Untuk tenaga pengajar dalam pengintegrasian ini diambil dari guru mata pelajaran dan ada juga yang didatangkan pengajar dari luar sekolah.

Walaupun begitu masih ada beberapa kendala yang dihadapi SMA Negeri 5 Padang, yaitu pertama, masalah alokasi dana dimana sekolah belum bisa meneluarkan anggaran secara maksimal, kedua, kendala yang dialami guru dalam mengintegrasikan budaya Minangkabau kedalam materi yang diajarkan karena tidak semua materi dapat diintegrasikan, ketiga yaitu tempat yang masih terbatas dan media yang masih sedikit dalam pengintegrasian tersebut, keempat tidak semua guru memiliki kemampuan setara dalam memahami budaya Minangkabau, kelima yaitu tempat yang masih terbatas untuk melaksanakan program pengintegrasian tersebut.

\section{Daftar Pustaka}

Abdurahman. (2011). Nilai-nilai Budaya dalam Kaba Minangkabau. Padang: UNP PRESS.

Fransyaigu, R. (2015). Penerapan Inkuiri Moral Berbasis Nilai-nilai Kearifan Lokal Minangkabau "Alam Takambang Jadi Guru" Untuk Pembentukan Karakter Siswa. Disertasi. Universitas Pendidikan Indonesia.

Ghony., D., \& Almanshur, M. (2016). Metodologi Penelitian Kualitatif. Yogyakarta: Ar-Ruzz 
Media.

Ilmi, D. (2015). Pendidikan Karakter Berbasis Nilai-Nilai Kearifan Lokal Melalui Ungkapan Bijak Minangkabau Darul Ilmi. Islam Realitas: Journal of Islamic \& Social Studies, 1(1), 4554. https://doi.org/http://dx.doi.org/10.30983/islam_realitas.v1i1.7

Crasswell, J.W. (2016). Pendekatan Metode Kualitatif, Kuantitatif, dan Campuran. Yogyakarta: Pustaka Belajar.

Khusna, N., Shufa, F., \& Artikel, S. (2018). Pembelajaran Berbasis Kearifan Lokal Di Sekolah Dasar: Sebuah Kerangka Konseptual. Jurnal Ilmiah Kependidikan, 1(1), 48-53. https://doi.org/10.24176/jino.v1i1.2316

Kunci, K. (2012). Pengembangan Pendidikan Karakter Dan Budaya Bangsa Berwawasan Kearifan Lokal. Jurnal Pendidikan Karakter, 1(1), 1-13. https://doi.org/10.21831/ jpk.v0i1.1307

Kusuma, R. S. (2018). Peran Sentral Kearifan Lokal dalam Peningkatan Kualitas Pendidikan. Pedagogik: Jurnal Pendidikan, 5(2), 228-239. https://doi.org/index.php/ 2528-5793

Muali, C. (2017). Rasionalitas Konsepsi Budaya Nusantara Dalam Menggagas Pendidikan Karakter Bangsa Multikultural. Jurnal Islam Nusantara, 1(1), 105. https://doi.org/10.3385 2/jurnalin.v1i1.64

Sulhan, M. (2018). Pendidikan Karakter Berbasis Budaya Dalam Menghadapi Tantangan Globalisasi. Visipena Journal, 9(1), 159-172. https://doi.org/10.46244/visipena.v9i1.450

Putri, Y., \& Fernandes, R. (2019). Pelaksanaan Integrasi Pendidikan Karakter Nilai Al-Qur'an dan Nilai Budaya Alam Minangkabau Dalam Pembelajaran Sosiologi (Studi Kasus: SMA Negeri 2 Padang dan SMA Adabiah Padang). Jurnal Sikola: Jurnal Kajian Pendidikan Dan Pembelajaran, 1(1), 1-6. https://doi.org/10.24036/sikola.v1i1.8

Sugiyono, S. (2009). Metode Penelitian Kuantitatif, Kualitatif, Dan R\&D. Bandung: Alfabeta.

Sulfemi, W. B. (2019). Manajemen Pendidikan Berbasis Multi Budaya. Journal of Chemical Information and Modeling, 53(9), 1689-1699. https://doi.org/10.1017/CBO9781107 415324.004

Tanu, I. K. (2016). Pembelajaran Berbasis Budaya Dalam Meningkatkan Mutu Pendidikan Di Sekolah. Jurnal Penjaminan Mutu, 2(1), 34. https://doi.org/10.25078/jpm.v2i1.59

Zulkifli, Z., \& Wirdanengsih, W. (2020). Pendidikan Karakter Melalui Kegiatan Ekstrakurikuler Tahfizd di SMA Negeri 5 Padang. Jurnal Sikola: Jurnal Kajian Pendidikan dan Pembelajaran, 1(3), 198-206. https://doi.org/10.24036/sikola.v1i3.23 